\title{
Role of cryoanalgesia in the control of pain after thoracotomy
}

\author{
J C ROXBURGH, C G MARKLAND, B A ROSS, W F KERR \\ From the Department of Thoracic Surgery, Norfolk and Norwich Hospital, Norwich
}

ABSTRACT Thoracotomy causes severe postoperative pain, which is difficult to manage since the $e_{\perp}^{\frac{i}{N}}$ use of systemic analgesics often causes respiratory depression. Cryoanalgesia of the intercostali nerves has been advocated as an effective means of local analgesia without serious side effects. A $N$ prospective randomised blind trial to investigate the efficacy of the technique was carried out. $\mathrm{A}$ 은 total of 53 patients undergoing thoracotomy were allocated to either the trial or a control group. At $\vec{D}$ thoracotomy the surgeon was informed of the patient's trial allocation. The trial group received one을. minute of direct cryotherapy to at least five intercostal nerves related to the incision. All patients $\overrightarrow{\vec{A}}$ received methadone via the lumbar epidural route in a dose calculated according to their weight. A@ linear analogue assessment of postoperative pain was made by the patients as soon as they weresufficiently awake. An independent record of all postoperative analgesia was kept. After dischargeo from hospital further assessments were made at least six weeks after operation. Statistical analysis of the scores of postoperative pain and analgesic consumption showed that there was no significant. difference between the trial and the control group. There was, however, a suggestion of an increase in the long term morbidity, although these figures were not amenable to statistical analysis. Thus it $\stackrel{2}{\Rightarrow}$ has not been possible to demonstrate a role for cryoanalgesia in the control of post thoracotomy 3 pain.

The control of postoperative pain is particularly important in thoracic surgery. Adequate postoperative analgesia must be provided without impairing the remaining respiratory function. There has therefore been some recent interest in local methods of pain relief. It has been shown by this unit that the use of epidural methadone is an effective and safe way of providing analgesia during the early postoperative phase. ${ }^{1}$ It cannot, however, be used for a prolonged period and therefore interest has been focused on cryoanalgesia, which has been said to provide pain relief for up to 26 days. ${ }^{2}$ Although there are favourable reports of its efficacy, ${ }^{34}$ the impression in this unit was that there was no subjective benefit. A prospective randomised trial was therefore devised to investigate the effect of adding cryoanalgesia to a standard postoperative analgesic regimen.

Address for reprint requests: Mr BA Ross, Department of Thoracic Surgery, Norfolk and Norwich Hospital, Norwich NR1 2BB.

Accepted 24 October 1986

\section{Patients and methods}

All patients over the age of 18 undergoing a tho racotomy were considered for entry into the trial. $A^{O}$ total of 60 patients were recruited and their informed consent was obtained. The trial numbers were ran-? domly allocated to either the cryoprobe or the controt group by the use of random numbers generated by a․ BBC microcomputer. Trial cards bearing the approN priate assignation were then sealed into numbered trial envelopes. At the time of the thoracotomy the patient was allocated a trial number and the contents of the appropriate envelope were revealed to the surgeon. Patients were operated on by one of two tho은 racic surgeons. The five or six intercostal nerves centred on the nerve of the incision were dissected out sufficiently far back to include the posterior rami and the drain sites were always included. Patients in the trial group received a standard 60 second direct appli $\frac{\rho}{\Phi}$ cation of the cryoprobe (Spembly BMS 40, Spembly Ltd, Andover, Hants) - an additional procedure ire the trial group. The tip of the cryoprobe was frozen to $-60^{\circ} \mathrm{C}$. The thoracotomy was closed in a standare 
Table 1 Arbitrary values used to derive scores of postoperative analgesia

\begin{tabular}{|c|c|}
\hline $\begin{array}{l}\text { Epidural methadone } \\
\text { Intramuscular opiates }\end{array}$ & $\begin{array}{l}10 \text { (high dose) } \\
8 \text { (low dose) }\end{array}$ \\
\hline $\begin{array}{l}\text { Dihydrocodeine } \\
\text { Buprenorphine }\end{array}$ & $\begin{array}{l}6 \text { (high dose) } \\
4 \text { (low dose) }\end{array}$ \\
\hline $\begin{array}{l}\text { Paracetamol } \\
\text { Aspirin }\end{array}$ & $\begin{array}{l}2 \text { (high dose) } \\
1 \text { (low dose) }\end{array}$ \\
\hline
\end{tabular}

manner. At the end of the procedure all patients in both groups had a lumbar epidural catheter inserted, and the appropriate dose of methadone was then administered according to the established practice of the unit (described by Welch ${ }^{1}$ ).

The patient was then returned to the ward, where no one was aware of the patient's trial allocation apart from the surgeon. All patients received appropriate analgesia on demand (table 1). Once the patients were sufficiently awake to cooperate, usually on the first postoperative morning, they were asked to estimate their degree of pain at regular times $(08.00$, $14.00,22.00 \mathrm{~h})$ by marking a standard $10 \mathrm{~cm}$ linear analogue pain scale. This procedure was repeated daily until discharge. A separate record of analgesic consumption was kept during this period and a daily numerical score was derived from the arbitrary values assigned to each analgesic (table 1).

After discharge from hospital a standard proforma was attached to the notes. Patients were seen about six weeks and six months after operation, when they were asked to mark a further linear analogue scale, which was used as an assessment of their degree of pain. Continuing analgesic consumption was also noted. The interviewer, who had no knowledge of the patient's trial allocation, also made a subjective assessment of the post-thoracotomy pain. On the basis of this the patients were classed as having "mild" (1-3), "moderate" (4-6), or "severe" (7-10) postthoracotomy pain (linear analogue scores shown in parentheses).

The analogue scores at $08.00 \mathrm{~h}$ on the first postoperative morning were arbitrarily designated as point zero and further points were then numbered sequentially. About 40 consecutive pain scores were obtained from each patient. Within the two groups the mean scores and standard deviations at each point were calculated; matching points were then compared by means of Student's $t$ test. The analgesic totals were then calculated on a daily basis to give about 14 totals for each patient. A daily mean and standard deviation for each pair of totals was obtained and these were compared with the Wilcoxon rank sum test. All statistical analysis was performed on a BBC microcomputer by means of the Datacalc package. Since the outpatient assessment was more subjective, a detailed statistical analysis of the results was not thought appropriate.

\section{Results}

Initially 60 patients were entered into the trial but seven of them were excluded because they were unable to complete the inpatient assessment. In five cases this was due to postoperative death and in two cases to severe postoperative problems such as chest wall bleeding and extensive chest wall resection. Of the remaining 53 patients, 23 received cryoanalgesia and 30 did not. The average age of the two groups was very similar, 59.9 (cryoanalgesia) and 60.3 years (control). There were 24 men in the control group and 16 in the trial group.

The types of operation performed and the relevant numbers of each are shown in table 2 .

About $85 \%$ of the possible recordings of linear analogue score were completed. The analgesic record was checked against the hospital drug charts and found to have an accuracy of over $95 \%$.

The means of the two individual parameters of pain - namely, the pain score and the analgesic totals for each observation-were plotted against time for the two populations. These are shown graphically in figures 1 and 2 . When postoperative pain is plotted against time it shows a biphasic decrease and this is mirrored by a similar decrease in analgesic consumption.

Statistical analysis shows there to be no significant difference at the $5 \%$ level, on any of the days, between the control and the trial group for either measurement.

The outpatient follow up at six weeks was good21 of 23 patients $(89 \%)$ in the trial group and 27 of 29 $(92 \%)$ in the control group attended for review. There was moderate to severe pain, as assessed by the method outlined above, in five of $21(23 \%)$ in the trial group as opposed to two of $27(7 \%)$ in control group. No statistical analysis was performed. By six months there had been no change in the post-thoracotomy pain of those who were assessed. The follow up rate was, however, low so no further analysis was made.

\section{Discussion}

The results from this trial show that the addition of cryoanalgesia to a standard postoperative regimen produces no significant reduction in either post-

Table 2 Numbers of patients having different types of operation in the cryotherapy and control groups

\begin{tabular}{lcc}
\hline Operations & Cryotherapy & Control \\
\hline Pulmonary resections & 13 & 16 \\
Oesophageal & 7 & 8 \\
Pleural & 2 & 4 \\
Others & 1 & 2 \\
Total & 23 & 30 \\
\hline
\end{tabular}




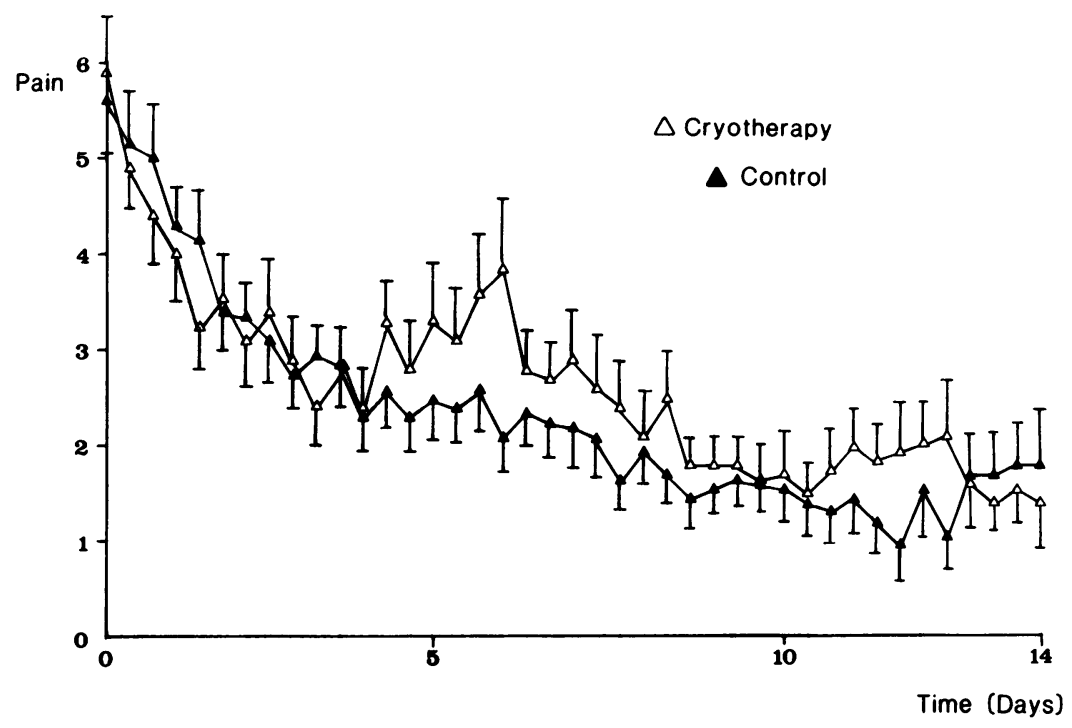

Fig 1 Graph showing mean postoperative pain indicated by linear analogue scores in 23 patients receiving cryotherapy to the intercostal nerves $(\triangle)$ and 29 controls $(\Delta)$. Bars indicate standard errors.

operative pain or analgesic consumption. This is at variance with previous findings which have suggested that cryoanalgesia is effective ${ }^{3-6}$; but it is consistent with recent work, ${ }^{7}$ which showed that there was no significant difference in pain relief between cryoanalgesia and a simple opiate infusion pump.
The measurement of pain is difficult, but the use of the linear analogue scale to measure severe pain is $\stackrel{\mathbb{}}{\varnothing}$ reliable ${ }^{8}$ and in particular the $10 \mathrm{~cm}$ scale, as used in $\Rightarrow$ this trial, has given the most satisfactory results. ${ }^{9}$ Other workers have judged postoperative pain by the amount of narcotic analgesia the patient required ino

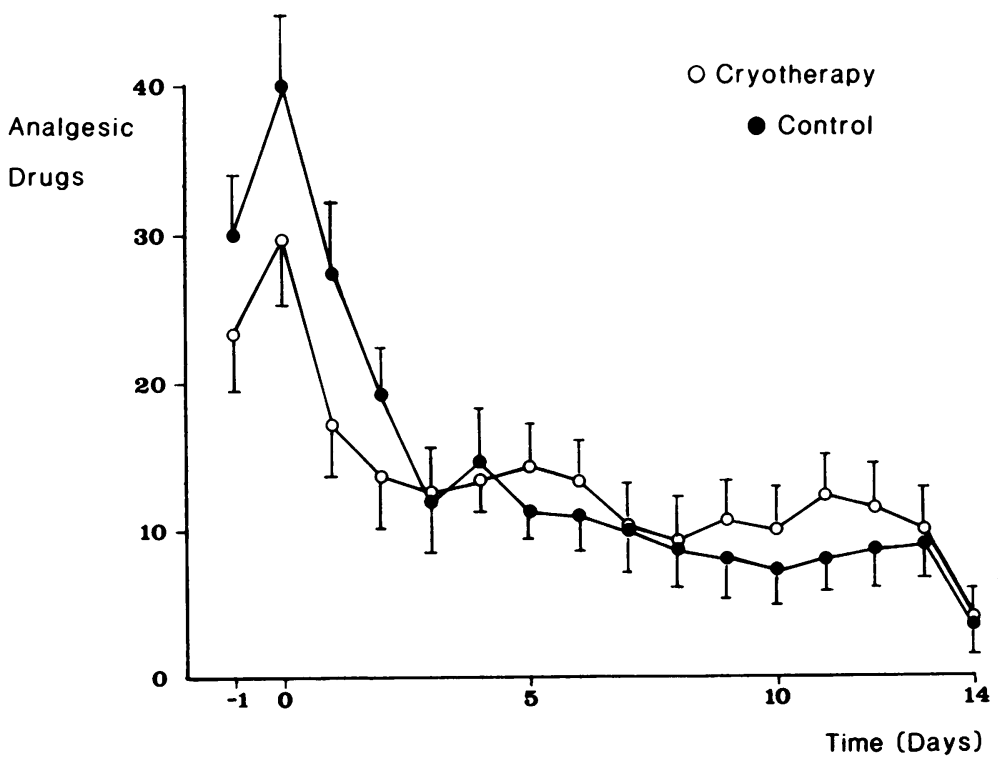

Fig 2 Graph showing mean analgesic consumption (arbitrary score units) in 23 patients receiving cryotherapy to the intercostal nerves ( $O$ ) and 29 controls (O). Bars indicate standard errors. 
the initial postoperative period, ${ }^{3}$ and in some cases this has been combined with a subjective assessment of pain by the patient. ${ }^{4}$ The fact that both epidural and systemic narcotics were given on a dose-weight basis enabled the postoperative analgesia to be numerically ranked, thus enabling objective analysis of drug requirement throughout the whole postoperative period. This arbitary ranking is open to criticism, but both graphs show similar changes with time and this lends credence to the technique. The timing of the various pain measurements is also variable. Some trials have made regular measurements on alternate days, ${ }^{5}$ others have made multiple recordings in the early postoperative phase with intermittent measurements over the remaining period. ${ }^{6}$ In this trial the methods were combined to provide an accurate objective assessment of pain throughout the postoperative period.

The technique of applying the cryoprobe was similar to that used in most of the trials claiming this technique to be beneficial, although one trial used a two minute freeze ${ }^{3}$ and in another a 30 second freezethaw cycle was repeated. ${ }^{4}$ The temperature to which the intercostal nerve is frozen and the duration of cryoprobe application have been matters for discussion. There is general agreement that interruption of conduction becomes prolonged at a temperature between $-5^{\circ}$ and $-20^{\circ} \mathrm{C}$. $^{10}$ The time required to produce an adequate cryolesion varies with the technique used but, provided that direct contact is obtained, and that the critical temperature of $-20^{\circ} \mathrm{C}$ is reached, a freezing time of one minute is sufficient. ${ }^{10}$ No additional benefit is gained from repetition of the freeze-thaw cycle. ${ }^{10}$

The long term results are worrying. Although the assessment of the patients was subjective, and therefore not amenable to statistical analysis, five patients did complain of severe or moderately severe neuralgia. This required continuing analgesic treatment and even referal to the pain relief clinic. Other prob- lems associated with this technique are an increase in operating time of about 15 minutes and the occasional production of appreciable chest wall bleeding, albeit in less than $5 \%$ of cases.

We have been unable to show that peroperative cryoanalgesia of the intercostal nerves produces short term benefit to patients and suspect that there may be increased long term morbidity.

We would like to thank Dr R Hanka, senior lecturer in medical statistics, Cambridge University, for his help with the statistical analysis of the results.

\section{References}

1 Welch DB, Hrynaszkiewicz A. Postoperative analgesia using epidural methadone. Administration by the lumbar route for thoracic pain relief. Anaesthesia 1981;36:1051-4.

2 Lloyd JW, Barnard JDW, Glynn CJ. Cryoanalgesia: a new approach to pain relief. Lancet 1976;ii:982-4.

3 Glynn CJ, Lloyd JW, Barnard JDW. Cryoanalgesia in the management of pain after thoracotomy. Thorax 1980;35:325-7.

4 Maiwand O, Makey AR. Cryoanalgesia for relief of pain after thoracotomy. Br Med J 1981;282:1749-50.

5 Katz J, Nelson W, Forest R, Bruce D. Cryoanalgesia for post thoracotomy pain. Lancet 1980;i:512-3.

6 Orr IA, Keenan DJM, Dundee JW, Patterson CC, Greenfield AA. Post thoracotomy pain relief: combined use of cryoprobe and morphine infusion techniques. Ann $R$ Coll Surg Engl 1983;65:366-9.

7 Orr IA, Keenan DJM, Dundee JW. Improved pain relief after thoracotomy: use of cryoprobe and morphine infusion. $\mathrm{Br}$ Med J 1981;283:945-8.

8 Revill SI, Robinson JO, Rosen M, Hogg MIJ. The reliability of a linear analogue for evaluating pain. Anaesthesia 1976;31:1191-8.

9 Scott J, Huskisson EC. Graphic representation of pain. Pain 1976;2:175-84.

10 Evans PJD. Cryoanalgesia. Anaesthesia 1981;36: 1003-13. 